\title{
Ultraviolet Spectrophotometric Method for Determination of Glipizide in Presence of Liposomal/Proliposomal Turbidity
}

\author{
Neelkant Prasad, Roshan Issarani, and Badri Prakash Nagori \\ Lachoo Memorial College of Science and Technology, Pharmacy Wing, Sector-A, Shastri Nagar, Jodhpur, Rajasthan 342003, India \\ Correspondence should be addressed to Neelkant Prasad; prasadneelkant@gmail.com
}

Received 27 May 2013; Revised 17 July 2013; Accepted 18 July 2013

Academic Editor: Renata Diniz

Copyright (C) 2013 Neelkant Prasad et al. This is an open access article distributed under the Creative Commons Attribution License, which permits unrestricted use, distribution, and reproduction in any medium, provided the original work is properly cited.

\begin{abstract}
A simple and sensitive ultraviolet spectrophotometric method for quantitative estimation of glipizide in presence of lipid turbidity is described to avoid false estimation due to diffraction by turbidity. UV detection was performed at $230 \mathrm{~nm}, 225 \mathrm{~nm}$, and $235 \mathrm{~nm}$, and the calibration curve was plotted between resultant of absorbance of $[230 \mathrm{~nm}-(225 \mathrm{~nm}+235 \mathrm{~nm}) / 2]$ and concentration of analyte. The calibration curve was linear over the concentration range tested $(1-20 \mu \mathrm{g} / \mathrm{mL})$ with limit of detection of $0.27 \mu \mathrm{g} / \mathrm{mL}$ and limit of quantification of $0.82 \mu \mathrm{g} / \mathrm{mL}$. Percent relative standard deviations and percent relative mean error, representing precision and accuracy, respectively, for clear as well as turbid solutions, were found to be within acceptable limits, that is, always less than 0.69 and 0.41 , respectively, for clear solution and 0.65 and 0.47 , respectively, for turbid solution. Conclusively, our method was successfully applied for the determination of glipizide in clear as well as turbid solutions, and it was found that the drug analyte in both types of solutions can be detected from the same calibration curve accurately and precisely and glipizide entrapped in the liposomes or in proliposomal matrix was not detected.
\end{abstract}

\section{Introduction}

The samples of dissolution of liposomes/proliposomes contain lipid turbidity, as the literature review revealed that the drug released is measured after separation of the lipid turbidity in cooling ultracentrifuges at high speeds $[1,2]$. During ultracentrifuge, at such a high speed, the liposomes might rupture and the drug is released to the dissolution medium all at once and can affect the actual concentration of the solution. Another method of dissolution of liposomes is using dialysis bags. The liposomal formulation is filled in the dialysis tubing, and both the ends of it are tied with the help of tying clips. The tied tubing is then dipped in the dissolution medium. The drug thus released does not take the liposomal turbidity with it in the dissolution medium and can be detected easily without any interference due to turbidity $[1,3]$. This method increases the evaluation cost by adding the cost of dialysis tubing.

Derivative spectrophotometric methods, difference spectrophotometry, and bichromatic methods can also be applied for elimination of background absorption and/or scattering, but all these methods are more or less complex. Also derivative spectrophotometry results in more complex spectrum.

Various methods from different researchers are available for assay of GLIP. Some of them $[4,5]$ have used nonaqueous solvents and can be used for assay of drug and formulations but are not suitable for assessment of aqueous dissolution samples. Available HPLC method by Shaodong et al. [6] can be used for the purpose but is a complex, expensive, and timeconsuming extraction procedure. Various procedures for aqueous sample assessment are also available [7-12], but none of them can be used for estimation of dissolution samples of the liposomes or proliposomes of the drug without separation of turbidity; that is, separation of turbidity is required for estimation by these methods because turbidity results in false estimation of the drug due to the fact that diffraction or dissolution studies would be carried out using dialysis bags so that turbidity does not reach the dissolution medium. A high-speed cooling ultracentrifuge is required for separation that might result in bursting of liposomes during separation leading to release of the entrapped drug all at once in the solution to give increased concentrations, and later one increases 
the cost of study by adding the cost of dialysis tubing. In the method by Phalke et al. (1997) [13], GLIP has derivatized by complexation with acridine yellow, and then the complex has been extracted in chloroform and then evaluated. Firstly, this method is time consuming, and, secondly, presence of lipid/turbidity might affect the complexation reaction. Henry et al. (2009) [14] estimated molar extinction coefficient of the drug that also requires a clear solution. Similarly, methods from other writers like Sköld et al. (2006) [15] and Vargas et al. (2000) [16] are also not suitable due to similar reasons for GLIP liposome/proliposome dissolution samples estimation directly along with turbidity present in it.

A simple, easy to calculate, ultraviolet spectrophotometric method is described here to eliminate the effect of lipid turbidity. The method is successfully applied to quantitatively estimate the drug in presence of lipid turbidity during dissolution as well as to determine drug content of the liposomes/proliposomal matrices. By this method the drug entrapped inside the liposomes/proliposomal matrices is not detected. Further, the same method is found to be applicable to quantitatively estimate the pure drug also. In the proposed method, there is no need to filter the samples to remove any undissolved drug before estimation because the undissolved drug in the samples does not absorb light, instead it diffracts.

In this method, the turbidity added from outside is in the form of blank processed lipid components of liposomes/proliposomes without drug in the appropriate ratio such that they form liposomes when come in contact with the aqueous medium. Now, as the lipid molecules self-assemble when they come in contact with the aqueous medium to make the lamellar bodies, the prepared turbid samples can be the proper model for real liposomal and proliposomal formulations.

\section{Experimental}

2.1. Materials and Methods. All chemicals used were of reagent grade. Glipizide was kindly gifted by Alkem Laboratories Limited, Taloja, Raigarh, Maharashtra, India.

Acetonitrile (ACN), double-distilled water, sodium hydroxide, and potassium-dihydrogenorthophosphate were procured from Loba Chemie Pvt. Ltd., Mumbai, India.

2.1.1. Stock Solution A. A $1000 \mu \mathrm{g} / \mathrm{mL}$ stock solution was prepared by dissolving $50 \mathrm{mg}$ GLIP in 3:1 ACN: Phosphate buffer $\mathrm{pH} 7.4$ in a $50.0 \mathrm{~mL}$ volumetric flask and making the volume upto the mark with the same solvent.

2.1.2. Stock Solution B. A $50 \mu \mathrm{g} / \mathrm{mL}$ working stock solution was prepared by diluting $12.5 \mathrm{~mL}$ of the stock solution A upto mark in a $250 \mathrm{~mL}$ volumetric flask with Phosphate buffer $\mathrm{pH}$ $7.4 \pm 0.1$.

2.1.3. Stock Solution C. A $50 \mu \mathrm{g} / \mathrm{mL}$ working turbid stock solution was prepared by adding $20 \mathrm{mg}$ of the blank, processed proliposomal components without drug to the previously prepared working stock solution $\mathrm{B}(50 \mu \mathrm{g} / \mathrm{mL})$ in a $100 \mathrm{~mL}$ volumetric flask. The solution was sonicated for 15 minutes and made the volume upto mark with the same stock so as to ensure a drug: lipid ratio of $20: 80$ (maximum in all working standards).

2.2. Instrumentation. A Shimadzu Pharmspec UV 1800 ultraviolet-visible spectrophotometer was used.

2.3. Method. Various aliquots of working stock solutions B and $\mathrm{C}$ were transferred to $10 \mathrm{~mL}$ volumetric flasks so as to prepare various alternate clear and turbid working standard dilutions of $1,1.5,2,3,4,6,8,12,16$, and $20 \mu \mathrm{g} / \mathrm{mL}$, and volume was made upto mark with phosphate buffer $\mathrm{pH} 7.4 \pm$ 0.1 . The calibration curve was prepared from these dilutions against clear blank by taking the absorbances of the prepared standard dilutions at three wavelengths, that is, wavelength of maximum absorption $\lambda_{\max }(230 \mathrm{~nm})$ and at two wavelengths equidistant on either side of $\lambda_{\max }$, that is, $225 \mathrm{~nm}$ and $235 \mathrm{~nm}$, taking the average of the later two, subtracting this average from the absorbance at $\lambda_{\max }$, and plotting the result against concentration.

\section{Results and Discussion}

The UV spectra of the prepared clear as well as turbid solutions of GLIP were run between $400 \mathrm{~nm}$ and $200 \mathrm{~nm}$. Both exhibited a prominent peak at $230 \mathrm{~nm}$ (Figure 1). The peak was very much clear in both spectra, so it was selected for further studies as $\lambda_{\max }$. Two other wavelengths of measurements used were $225 \mathrm{~nm}$ and $235 \mathrm{~nm}$ (equidistant on either side of $\lambda_{\max }$ ), and the standard curve was prepared by plotting corrected absorbance $\left[A_{230}-\left(A_{225}+A_{235}\right) / 2\right]$ on $y$-axis against concentration on $x$-axis (Figure 2). The Beer's law was validated from $1-20 \mu \mathrm{g} / \mathrm{mL}$. The dilutions were prepared as alternate clear and turbid to prove that the effect of turbidity had been overcome. The linear regression equation was found to be $y=0.00533 x+0.00009$ where $A$ is the absorbance and $x$ is the concentration. The detection limit and limit of quantification determined with acceptable accuracy and precision were 0.27 and $0.82 \mu \mathrm{g} / \mathrm{mL}$, respectively. The low values of limit of detection (LOD) and limit of quantification (LOQ) showed negligible scatter of points with respect to line of regression. The method was validated for assessment of both clear as well as turbid solutions, and within acceptable range validation parameters indicated that the developed method was specific, rapid, reliable, accurate, precise, and reproducible.

3.1. Method Validation. The validity of the method for linearity, specificity, accuracy, repeatability, and precision according to recommendations was tested (ICH Guidelines Q2 (R1), 2005) [17]. The results are shown in Tables 1-4. The LOD was determined by establishing the minimum level at which the analyte can be reliably detected. The LOD and LOQ were calculated according to the following equation:

$$
\begin{aligned}
& \mathrm{LOD}=\left(3.3\left(\frac{\mathrm{SD}_{\text {intercept }}}{\text { Slope }}\right)\right), \\
& \mathrm{LOQ}=\left(10\left(\frac{\mathrm{SD}_{\text {intercept }}}{\text { Slope }}\right)\right),
\end{aligned}
$$


TABLE 1: Analytical parameters for determination of GLIP using the proposed method.

\begin{tabular}{lc}
\hline Parameter & Value \\
\hline Analytical wavelengths $(\mathrm{nm})$ & 225,230, and 235 \\
Equation used for standard curve & $A 230-(A 225+A 235) / 2$ \\
Linearity range $(\mu \mathrm{g} / \mathrm{mL})$ & $1-20$ \\
Regression equation $(A=a C+b)^{\mathrm{a}}$ & \\
$\quad$ Slope $(a)$ & 0.00533 \\
$\quad$ Intercept $(b)$ & 0.00009 \\
SD of intercept $(n=6)$ & $4.39 \times 10^{-4}$ \\
LOD $\left(3.3\left(\mathrm{SD}_{\text {intercept }} / \mathrm{Slope}\right)\right)(\mu \mathrm{g} / \mathrm{mL})$ & 0.27 \\
LOQ $\left(10\left(\mathrm{SD}_{\text {intercept }} / \mathrm{Slope}\right)\right)(\mu \mathrm{g} / \mathrm{mL})$ & 0.82 \\
Correlation coefficient & 0.99929 \\
\hline
\end{tabular}

${ }^{\mathrm{a}} A$ : absorbance and $C$ : concentration.

TABLE 2: Test for residuals.

\begin{tabular}{lcc}
\hline $\begin{array}{l}\text { Predicted conc. } \\
(\mu \mathrm{g} / \mathrm{mL})\end{array}$ & $\begin{array}{c}\text { Observed conc. } \\
(\mu \mathrm{g} / \mathrm{mL})\end{array}$ & $\begin{array}{c}\text { Residual amount } \\
(\mu \mathrm{g} / \mathrm{mL})\end{array}$ \\
\hline 1 & 1.202627 & 0.202627 \\
1.5 & 1.571607 & 0.071607 \\
2 & 2.057849 & 0.057849 \\
3 & 2.9803 & -0.0197 \\
4 & 4.010632 & 0.010632 \\
6 & 5.852408 & -0.14759 \\
8 & 7.777048 & -0.22295 \\
12 & 11.99312 & -0.00688 \\
16 & 15.77236 & -0.22764 \\
20 & 20.32395 & 0.323952 \\
\hline
\end{tabular}

where $\mathrm{SD}_{\text {intercept }}$ is standard deviation of the intercept of regression line and Slope is the slope of calibration curve. The proposed method was evaluated for the linearity (linear regression analysis as shown in Table 1 as well as test for residuals as shown in Table 2 and Figure 3, accuracy as percent relative mean error (\%RME), and the precision as percent relative standard deviation (\%RSD) (Table 3). The recovery studies were also performed for the developed method (Table 4).

3.2. Linearity. The curve was found to be linear as shown by linear regression equation and the regression coefficient of the formed standard curve as shown in Table 1. The linearity was also proved by test for residuals. A random pattern of residuals supports the linearity [18] as shown in Table 2 and Figure 3.

3.3. Accuracy and Precision. To test the accuracy and precision of the proposed method a certain amount of GLIP was assayed by the proposed method three different times a day (intraday accuracy and precision) and three different days (interday accuracy and precision) in both clear and turbid solutions. The low values of \%RME (represents accuracy) and \%RSD (represents precision) indicate that the developed method is accurate as well as precise. Table 3 shows the obtained values for accuracy (\%RME always less than 0.41

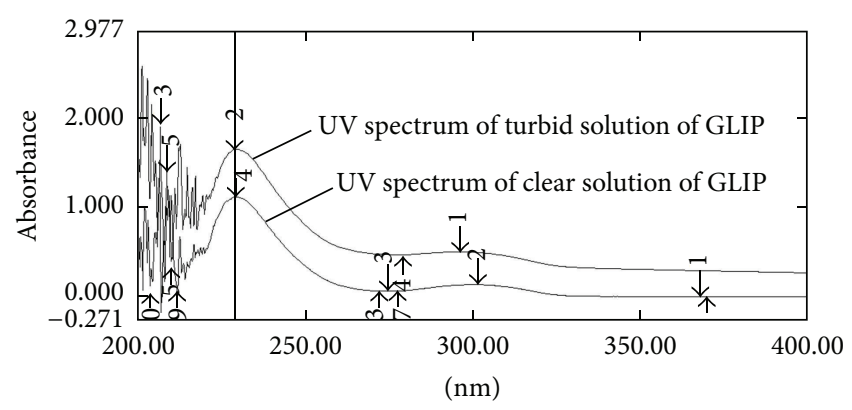

FIGURE 1: Overlain UV spectra of clear and turbid solutions of glipizide.

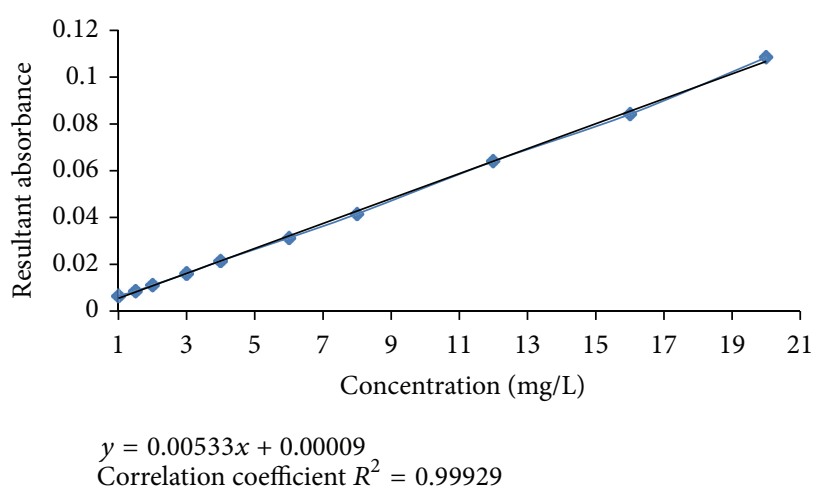

FIGURE 2: Standard curve.

and 0.47 for clear and turbid solutions, resp.) and precision (\%RSD always less than 0.69 and 0.65 for clear and turbid solutions, resp.). The repeatability and reproducibility of the given method are fairly good as indicated by the low values of $\%$ RSD and \%RME.

3.4. Repeatability/Reproducibility. The repeatability and reproducibility of the given method are fairly good as indicated by the low values of \%RSD and \%RME.

3.5. Specificity. As turbidity from outside was added to the alternate dilutions and the rest of validation parameters were within acceptable ranges, the method can be said to be specific.

3.6. Robustness of the Method. The robustness of the method adopted is demonstrated by the consistency of the absorbance with the deliberate minor changes in the experiment, such as sonication time and $\mathrm{pH}$ of the buffer by \pm 1 .

3.7. Recovery Studies. The recovery studies were performed by adding known amounts of the drug to the preanalysed samples from pure drug and in-house preparation at three different levels, that is, $80 \%, 100 \%$, and $120 \%$ (standard addition method). The mean recoveries for GLIP were determined for both clear and turbid solutions (Table 4) and were found to be within acceptable limits, that is, $99.02 \%$ to $101.08 \%$ for clear solution and $99.11 \%$ to $101.00 \%$ for turbid solution. 
TABLE 3: Precision and accuracy of proposed method $(n=6)$.

\begin{tabular}{|c|c|c|c|c|c|c|c|}
\hline \multirow{2}{*}{ Solution } & \multirow{2}{*}{$\begin{array}{l}\text { Conc. analysed } \\
(\mu \mathrm{g} / \mathrm{mL})\end{array}$} & \multicolumn{3}{|c|}{ Intraday (Analyst 1) } & \multicolumn{3}{|c|}{ Interday (Analyst 2) } \\
\hline & & $\begin{array}{c}\text { Found } \pm \text { S.E. }{ }^{a, b} \\
(\mu \mathrm{g} / \mathrm{mL})\end{array}$ & $\begin{array}{c}\text { Precision } \\
(\% \text { RSD })\end{array}$ & $\begin{array}{r}\text { Accuracy } \\
\text { (\%RME) }\end{array}$ & $\begin{array}{c}\text { Found } \pm \text { S.E. }{ }^{a, b} \\
(\mu \mathrm{g} / \mathrm{mL})\end{array}$ & $\begin{array}{c}\text { Precision } \\
(\% \text { RSD })\end{array}$ & $\begin{array}{r}\text { Accuracy } \\
\text { (\%RME) }\end{array}$ \\
\hline \multirow{3}{*}{$\begin{array}{l}\text { Clear } \\
\text { solution }\end{array}$} & 5 & $5.02 \pm 0.01$ & 0.69 & 0.35 & $5.02 \pm 0.01$ & 0.61 & 0.41 \\
\hline & 10 & $10.02 \pm 0.02$ & 0.40 & 0.24 & $10.04 \pm 0.02$ & 0.53 & 0.39 \\
\hline & 15 & $15.05 \pm 0.03$ & 0.52 & 0.32 & $15.05 \pm 0.03$ & 0.44 & 0.30 \\
\hline \multirow{3}{*}{$\begin{array}{l}\text { Turbid } \\
\text { solution }\end{array}$} & 5 & $5.02 \pm 0.01$ & 0.61 & 0.35 & $5.02 \pm 0.01$ & 0.65 & 0.47 \\
\hline & 10 & $10.04 \pm 0.02$ & 0.39 & 0.39 & $10.04 \pm 0.03$ & 0.61 & 0.45 \\
\hline & 15 & $15.06 \pm 0.03$ & 0.50 & 0.43 & $15.06 \pm 0.04$ & 0.61 & 0.39 \\
\hline
\end{tabular}

average of six determinations.

${ }^{\mathrm{b}}$ Mean \pm standard error.

\%RSD: percentage relative standard deviation.

\%RME: percentage relative mean error.

TABLE 4: Recovery of the proposed method (standard addition method, $n=6$ ).

\begin{tabular}{|c|c|c|c|}
\hline Dosage forms & $\begin{array}{c}\text { Concentration taken, } \\
C_{s}(\mu \mathrm{g} / \mathrm{mL}) \\
\end{array}$ & $\begin{array}{c}\text { Concentration added, } \\
C_{a}(\mu \mathrm{g} / \mathrm{mL}) \\
\end{array}$ & $\begin{array}{c}\text { Proposed method } \\
\text { \%Recovery }{ }^{\mathrm{a}, \mathrm{b}} \pm \text { \%RD }\end{array}$ \\
\hline \multirow{4}{*}{ Pure GLIP } & \multirow{4}{*}{ 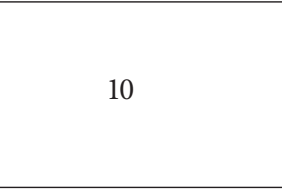 } & - & $100.24 \pm 0.40$ \\
\hline & & 8 & $101.08 \pm 0.62$ \\
\hline & & 10 & $99.18 \pm 0.51$ \\
\hline & & 12 & $99.02 \pm 0.53$ \\
\hline \multirow{4}{*}{ Proliposomes of GLIP } & \multirow{4}{*}{10} & - & $100.39 \pm 0.39$ \\
\hline & & 8 & $101.00 \pm 0.64$ \\
\hline & & 10 & $99.39 \pm 0.68$ \\
\hline & & 12 & $99.11 \pm 0.55$ \\
\hline
\end{tabular}

${ }^{a}$ Average of six determinations.

$\mathrm{b}_{\%}$ recovery $=\left[\left(C_{t}-C_{s}\right) / C_{a}\right] \times 100$, where $C_{t}$ : total concentration, $C_{s}$ : concentration taken, and $C_{a}$ : concentration added.

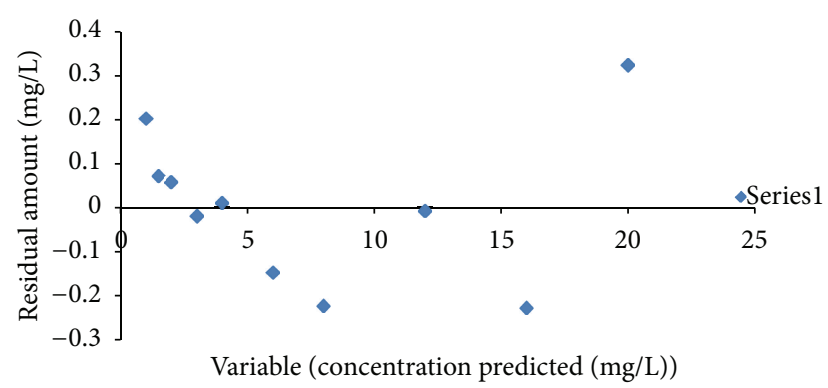

FIgURE 3: Residual amount v/s variable curve.

3.8. Nondetection of Analyte That Was Entrapped inside the Formulation. The in-house formulation was added to a known sample and detected by the proposed method. It was found that the entrapped analyte was not detected by the proposed method.

\section{Conclusion}

The proposed method has been proved to be simple, precise, rapid, and reliable. The method was validated by evaluation of the validation parameters as described in the ICH2QR guideline [17] for specificity, linearity, LOD values, LOQ values, inter- and intraday precision, and accuracy which were obtained during the validation studies and were found to be within acceptable limits.

Moreover, the method is fast with respect to analysis time as compared to sophisticated chromatographic techniques. No expensive instrumentation and no expensive organic solvents are required.

The method can be successfully employed for GLIP quantification in all types of pharmaceutical formulations and liquid samples of GLIP.

\section{Acknowledgment}

Authors are thankful to Alkem Laboratories Limited, Taloja, Raigarh, Maharashtra, India, for providing a gift sample of GLIP.

\section{References}

[1] M. M. Nounou, L. K. El-Khordagui, N. A. Khalafallah, and S. A. Khalil, "In vitro release of hydrophilic and hydrophobic drugs from liposomal dispersions and gels," Acta Pharmaceutica, vol. 56, no. 3, pp. 311-324, 2006. 
[2] M. P. Ramprasad, G. M. Anantharamaiah, D. W. Garber, and N. V. Katre, "Sustained-delivery of an apolipoprotein Epeptidomimetic using multivesicular liposomes lowers serum cholesterol levels," Journal of Controlled Release, vol. 79, no. 1-3, pp. 207-218, 2002.

[3] R. J. Mumper and A. S. Hoffman, "The stabilization and release of hirudin from liposomes or lipid-assemblies coated with hydrophobically modified dextran," AAPS PharmSciTech, vol. 1, no. 1, article E3, 2000.

[4] L. Adhikari, S. Jagadev, S. Sahoo, P. N. Murthy, and U. S. Mishra, "Devlopement and validation of UV-visible spectrophotometric method for simultaneous determination of pioglitazone hydrochloride, metformin hydrochloride and glipizide in its bulk and pharmaceutical dosage form," International Journal of ChemTech Research, vol. 4, no. 2, pp. 625-630, 2012.

[5] A. Gumieniczek and A. Berecka, "Comparison of capillary electrophoresis and UV derivative spectrophotometry for determination of pioglitazone, glipizide and repaglinide," Annales Universitatis Mariae Curie-Sklodowska DDD, vol. 24, no. 1, pp. 15-23, 2011.

[6] J. Shaodong, W. J. Lee, J. W. Ee, J. H. Park, S. W. Kwon, and J. Lee, "Comparison of ultraviolet detection, evaporative light scattering detection and charged aerosol detection methods for liquid-chromatographic determination of anti-diabetic drugs," Journal of Pharmaceutical and Biomedical Analysis, vol. 51, no. 4, pp. 973-978, 2010.

[7] D. R. Rathod, M. N. Dole, and S. D. Sawant, "Spectrophotometric determination of glipizide in bulk and tablet dosage form by absorption maxima, first order derivative spectroscopy and area under the curve," Asian Journal of Pharmaceutical and Clinical Research, vol. 5, supplement 3, pp. 102-104, 2012.

[8] T. T. Chungath, Y. P. Reddy, and N. Devanna, "Simultaneous spectrophotometric estimation of metformin hydrochloride and glipizide in tablet dosage forms," International Journal of PharmTech Research, vol. 3, no. 4, pp. 2064-2067, 2011.

[9] A. Aruna and K. Nancey, "Simultaneous estimation of metformin HCL and glipizide in solid dosage forms by ultraviolet spectrophotometry," Indian Drugs, vol. 37, no. 11, pp. 533-536, 2000.

[10] H. N. Shivakumar, B. G. Desai, S. Pandya, and S. S. Karki, "Influence of $\beta$-cyclodextrin complexation on glipizide release from hydroxypropyl methylcellulose matrix tablets," PDA Journal of Pharmaceutical Science and Technology, vol. 61, no. 6, pp. 472491, 2007.

[11] R. K. Verma and S. Garg, "Selection of excipients for extended release formulations of glipizide through drug-excipient compatibility testing," Journal of Pharmaceutical and Biomedical Analysis, vol. 38, no. 4, pp. 633-644, 2005.

[12] A. E. M. Radi and S. H. Eissa, "Voltammetric and spectrophotometric studies on the inclusion complex of glipizide with $\beta$ cyclodextrin," Eurasian Journal of Analytical Chemistry, vol. 6, no. 1, pp. 13-21, 2011.

[13] P. N. Phalke, A. V. Sherikar, and P. M. Dhadke, "Direct spectrophotometric analysis of glipizide and phenformin hydrochloride in pharmaceutical dosage forms," Indian Journal of Pharmaceutical Sciences, vol. 59, no. 1, pp. 18-21, 1997.

[14] B. Henry, C. Foti, and K. Alsante, "Can light absorption and photostability data be used to assess the photosafety risks in patients for a new drug molecule?" Journal of Photochemistry and Photobiology B, vol. 96, no. 1, pp. 57-62, 2009.

[15] C. Sköld, S. Winiwarter, J. Wernevik et al., "Presentation of a structurally diverse and commercially available drug data set for correlation and benchmarking studies," Journal of Medicinal Chemistry, vol. 49, no. 23, pp. 6660-6671, 2006.

[16] F. Vargas, H. Méndez, E. Tropper, M. Velázquez, and G. Fraile, "Studies on the in vitro phototoxicity of the antidiabetes drug glipizide," In Vitro and Molecular Toxicology, vol. 13, no. 1, pp. 17-24, 2000.

[17] ICH Guidelines Q2 (R1), "Validation of analytical procedures: text and methodology," in ICH Harmonized Tripartite Guidelines, 2005.

[18] "Variations of linearity," http://people.duke.edu/ rnau/testing. htm. 

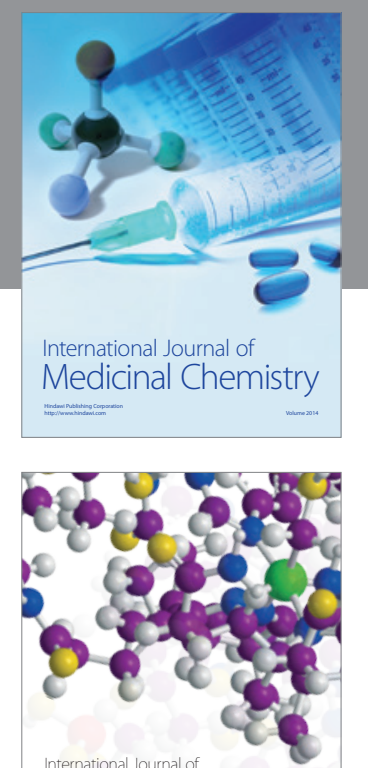

\section{Carbohydrate} Chemistry

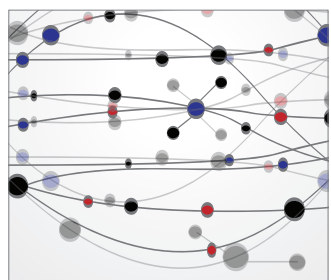

The Scientific World Journal
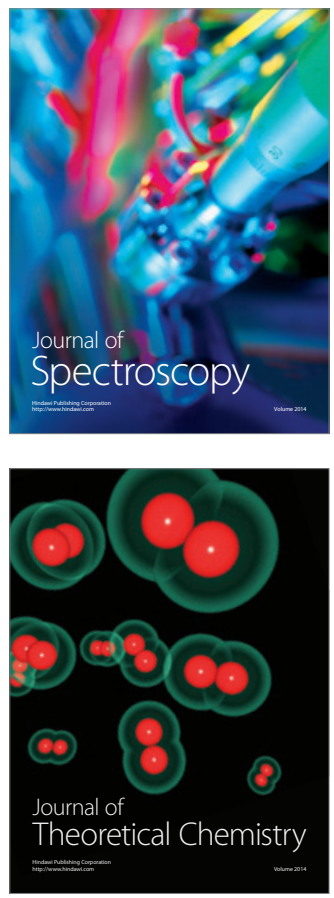
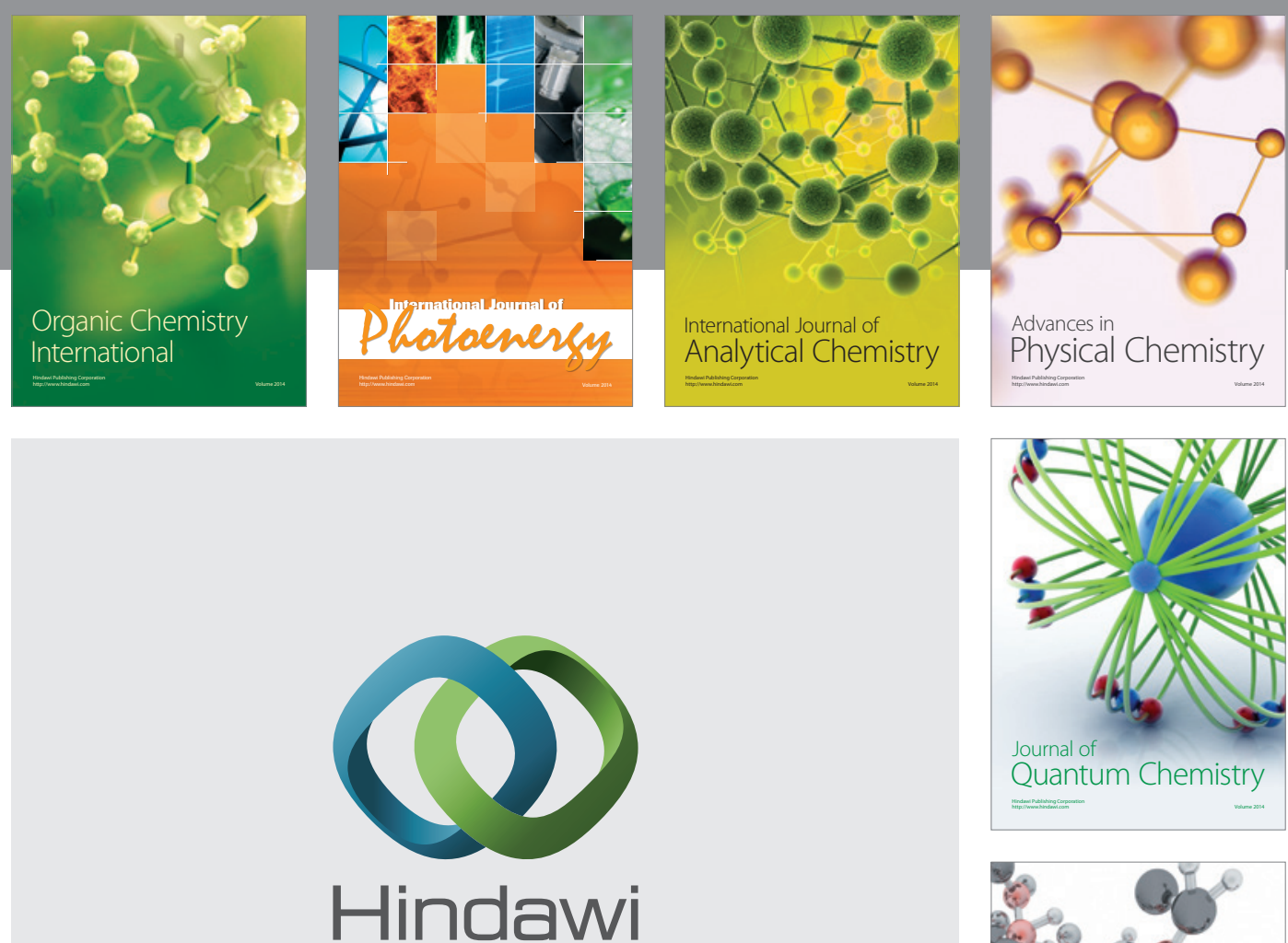

Submit your manuscripts at

http://www.hindawi.com

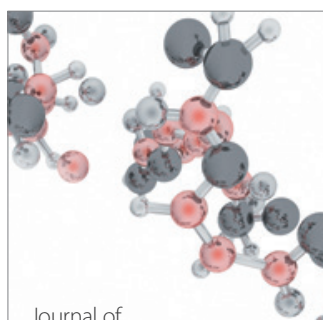

Analytical Methods

in Chemistry

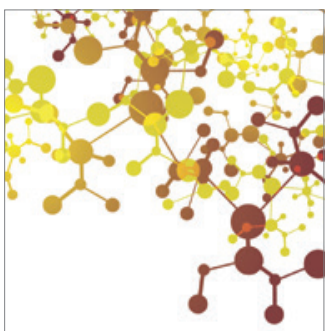

Journal of

Applied Chemistry

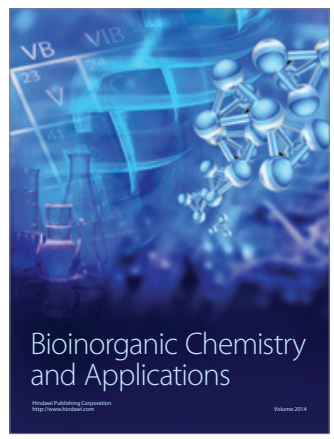

Inorganic Chemistry
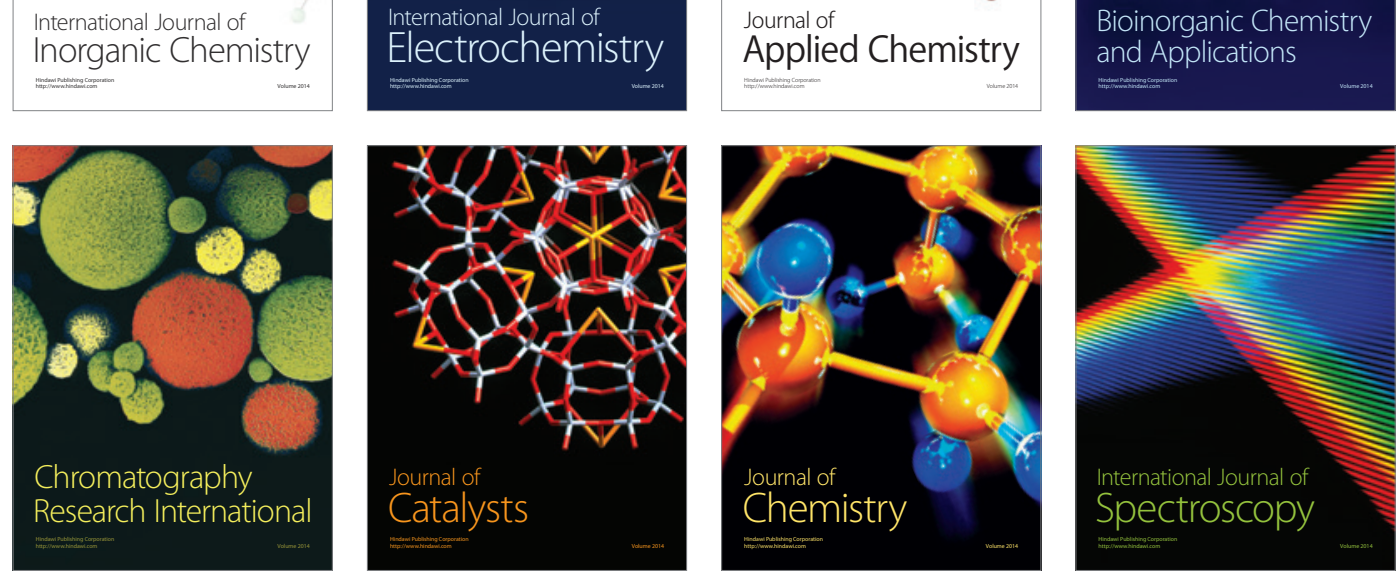